\title{
Detection of Mycobacterium avium Subspecies paratuberculosis: Comparing Fecal Culture Versus Serum Enzyme-Linked Immunosorbent Assay and Direct Fecal Polymerase Chain Reaction
}

\author{
D. L. Clark Jr., ${ }^{1}$ J. J. Koziczkowski, R. P. Radcliff, R. A. Carlson, and J. L. E. Ellingson ${ }^{2}$ \\ Marshfield Clinic Applied Sciences, 1000 N. Oak Ave., Marshfield, WI 54449
}

\begin{abstract}
Mycobacterium avium ssp. paratuberculosis (MAP) is the etiologic agent of Johne's disease in cattle. The disease causes diarrhea, reduced milk production, poor reproductivity, emaciation, and eventually death. Culture on Herrold's egg yolk agar is considered to be the definitive test for diagnosis of Johne's in cattle. This method has moderate sensitivity (30 to 50\%) and is $100 \%$ specific; however, it can take up to 16 wk due to the slow growth of MAP. Currently, serum ELISA is used to screen herds for Johne's disease, but positive tests must be confirmed culturally or by PCR. The current research sought to evaluate an in-house direct fecal PCR procedure and directly compare it to ELISA using culture as the gold standard. Serum and fecal samples were collected from cows $(n=250)$ with unknown Johne's status. Fecal samples were processed for culture on Herrold's egg yolk agar and direct PCR. Serum samples were tested using the Parachek serum ELISA. Overall, 67/250 [26.8\%, 95\% confidence interval (CI) 21.4 to 32.8] animals were culturally confirmed to be shedding MAP. The PCR and ELISA detected 74/250 $(29.6 \%, 95 \%$ CI 24 to 35.7$)$ and 25/250 (10\%, 95\% CI 6.6 to 14.4), respectively. Culture and PCR were able to detect more positive animals than ELISA. Overall, direct fecal PCR was $70.2 \%$ sensitive and $85.3 \%$ specific when using culture as the gold standard. The ELISA method was $31.3 \%$ sensitive and $97.8 \%$ specific. When culture reported $<10 \mathrm{cfu}$, the sensitivity and specificity of PCR and ELISA were 57.1 and $85.3 \%$, and 4.8 and $97.8 \%$, respectively. When culture reported 10 to $<40$ cfu, the sensitivity of PCR and ELISA were 75 and $50 \%$, respectively. When culture reported $\geq 40 \mathrm{cfu}$, the sensitivity of PCR and ELISA were 100 and $88.2 \%$, respectively. Specificity could not be calculated at these
\end{abstract}

\footnotetext{
Received November 28, 2007.

Accepted April 4, 2008.

${ }^{1}$ Corresponding author: clark.dorn@marshfieldclinic.org

${ }^{2}$ Current address: Kwik Trip Inc., Food Safety and Quality Assurance Department, La Crosse, WI 54602.
}

levels because there were no negative samples. The direct PCR outperformed the ELISA in detecting animals potentially infected with MAP and was not significantly different when compared with culture. The direct fecal PCR method described here provides faster results than traditional culture and is more sensitive than ELISA at detecting animals suspected of Johne's disease. These data support the use of PCR as an alternative method for screening herds for prevalence and diagnosis of Johne's disease.

Key words: Mycobacterium paratuberculosis, detection, enzyme-linked immunosorbent assay, polymerase chain reaction

\section{INTRODUCTION}

Mycobacterium avium ssp. paratuberculosis (MAP) is the etiologic agent of Johne's disease in cattle. The disease causes diarrhea, reduced milk production, poor reproductivity, emaciation, and eventually death. According to the USDA, MAP is estimated to have a herd prevalence of $21.6 \%$ (NAHMS, 1996) and causes an estimated loss of $\$ 1.5$ billion to the agricultural industry every year (Harris and Barletta, 2001). The usual route of infection is fecal-oral, with young animals becoming infected by contact with infected adults during suckling or by ingestion of MAP from the contaminated environment. The disease manifests in adult cows and results in economic losses caused by premature culling, reduced milk production, and loss of body weight in cattle sold for slaughter (Raizman et al., 2004).

The ability to detect MAP accurately and rapidly is an integral part of herd management. However, detection and control of this bacterium is complicated due to its slow division time and its ability to persist in the environment. Although MAP does not propagate in the environment, it survives for long periods in different environmental conditions (Raizman et al., 2004). Reports have described long-term MAP survival under various in vitro conditions expected on many dairy farms, including water, urine, manure, and below freezing temperatures (Larsen et al., 1956; Jorgensen, 1977). A re- 
cent report showed MAP could survive and propagate for up to $4 \mathrm{yr}$ in protozoa (Mura et al., 2006). Because MAP is shed into the environment by dairy cattle through fecal contamination and appears to survive well, a better understanding of MAP distribution in the environment could lead to improved herd screening alternatives (Raizman et al., 2004).

Effective detection of subclinical cases of bovine Johne's disease is a critical step in the reduction of disease prevalence in dairy herds (Eamens et al., 2000). Detection of subclinical infections will allow infected animals to be removed from the herd sooner and reduce exposure of the younger susceptible animals. However, current detection methodologies are inadequate for effective herd management because of poor sensitivity or long time to results. Immunologic assays such as ELISA, which rely on the presence of antibodies to MAP in the serum, are commonly used to diagnose paratuberculosis in a herd. However, because infected animals generally do not produce measurable antibody titers until the latter stages of disease, these tests are ineffective in detecting subclinical infections in a herd (Stabel, 1997). This lag time for disease detection allows for increased environmental contamination due to fecal shedding. Culture methods, although not ideal with an estimated sensitivity between 30 and $50 \%$ and specificity of $100 \%$ (Whitlock et al., 2000), are considered the definitive test for the diagnosis of Johne's disease (Collins, 1996). In addition, competing bacterial and fungal contamination often overgrow fecal cultures for MAP, making them unreadable (Stabel et al., 2002). Because most cattle with Johne's disease typically shed the microorganism intermittently in their feces and in low numbers, particularly in the early stages of disease, the sensitivity of fecal culture for properly diagnosing this disease in infected cows is estimated at 45 to $50 \%$ (Sockett et al., 1992). Conventional PCR methods using primer targets, such as 16S rRNA (Miller et al., 1999), IS900 (Miller et al., 1999; Green et al., 1989), $h s p X$ (Miller et al., 1999; Ellingson et al., 1998), and IS1311 (Whittington et al., 2001), have also been used as diagnostic tools. There is strong incentive to develop practical, sensitive, low-cost diagnostic methods, particularly methods that can be applied efficiently to define the status of whole herds in a timely manner (Whittington et al., 2000).

Herd control strategies focusing on the reduction of MAP transmission within the dairy farm environment through risk assessment-based changes in herd management have been developed. However, paratuberculosis continues to spread across US dairy herds because of widespread movement of cattle (Wells et al., 2003). This frequent movement of cattle between herds, often without knowledge of the prevalence of paratuberculo- sis infection, indicates the importance of valid categorization of herds on the basis of infection status to identify low-risk herds for purchase of replacement cattle. The US voluntary Johne's disease herd status program for cattle was designed to identify noninfected or low-risk herds (Bulaga, 1998). The testing protocol involves testing a subset of adult cattle in a herd using a serum ELISA to detect antibodies against MAP, and cattle with positive ELISA results are tested by bacteriologic culture of feces to confirm the presence of MAP. Individual-cow bacteriologic culture of feces provides advantages of increased test sensitivity and $100 \%$ test specificity (Whitlock et al., 2000) but at a higher cost and much longer turnaround time. Another herd testing strategy involves bacteriologic culture of pooled fecal samples. The primary advantage of pooling is that a higher percentage of animals can be represented within a tested population for a certain fixed laboratory cost (Wells et al., 2002). Pooling of fecal samples is especially compelling for large whole herd testing. The low sensitivity of ELISA tests and low detectable within-herd prevalence of infection in herds has created a demand for sensitive yet low-cost test strategies for herd detection (Christensen and Gardner, 2000).

Polymerase chain reaction is one method that can be used to overcome some of the disadvantages of the testing methods currently available. Direct fecal PCR can be completed in a single day and used as a diagnostic tool to detect the presence of MAP in animals suspected of having Johne's disease. The primary objective of this project was to estimate the sensitivity and specificity of the direct PCR test using Herrold's egg yolk agar (HEYA) culture as the gold standard. A secondary objective was to compare the abilities of direct PCR and serum ELISA to correctly identify animals shedding varying amounts of MAP using HEYA culture as the definitive test.

\section{MATERIALS AND METHODS}

\section{Sample Size and Sample Collection}

Sample size was determined using the statistical software package PASS 6.0 (NCSS, East Kaysville, UT) and the following criteria: If a sensitivity rate of $80 \%$ or higher is of interest, 246 independent samples are needed to be $95 \%$ confident that the observed sensitivity rate of $80 \%$ is within $5 \%$ of the true but unknown sensitivity, given a type-I error rate of $5 \%$.

To collect samples that would represent a broad range of MAP shedding in feces, clinic scientists and collaborating veterinarians collected a total of 250 bovine fecal samples and 250 serum samples from 2 dairy farms in Wisconsin. One farm had never had animals tested for Johne's except for diagnosis of suspicious animals and 
was suspected of having a relatively high prevalence of cows shedding MAP based on veterinarian assessment. The second farm was suspected of having a low number of cows shedding MAP due to its policy of conducting whole herd ELISA testing each year followed with culture confirmation of any animals with a positive ELISA result. All animals culturally confirmed to be shedding MAP were culled. The first farm was milking approximately 200 cows, head-locks were set after morning milking and samples were collected from the first 119 cows to lock up. The second farm was milking approximately 280 cows and samples were collected from 131 cows randomly chosen from 2 different tie-stall barns and one free-stall barn. All cows, regardless of farm, were at least $2 \mathrm{yr}$ old and lactating at the time of fecal and blood collection. Fecal samples were collected from inside the rectum by hand using a new nitrile glove for each cow. The fecal samples were immediately placed in individual sterile 100-mL containers (Tyco Healthcare, Mansfield, MA). Blood was collected from the coccygeal vein of each cow using a vacutainer tube (Becton Dickinson, Franklin Lakes, NJ). All samples (fecal and blood) were placed in coolers with icepacks and transported directly to the laboratory.

\section{Sample Preparation and Processing}

All fecal and serum samples were taken to Marshfield Clinic Laboratories-Food Safety Services (MCL-FSS). Fecal samples were processed for detection of MAP using bacterial culture and direct PCR. Serum samples were shipped to The Rocky Mountain Regional Animal Health Laboratory (Denver, CO) for ELISA testing. Fecal samples were frozen and stored at $-80^{\circ} \mathrm{C}$ (less than 2 wk) until processing.

The outside of each fecal sample vial was decontaminated with LPH (Steris Corporation, St. Louis, MO). The samples and controls were given a lab identification number. Each sample vial was aseptically opened, and approximately $2 \mathrm{~g}$ of fecal material was removed for analysis using the USDA culture method and an additional $2 \mathrm{~g}$ was removed for direct PCR (described later).

\section{Bacterial Culture}

Two grams of each fecal sample was placed into 35 $\mathrm{mL}$ of sterile water in a $50-\mathrm{mL}$ plastic conical tube and hand shaken vigorously for $15 \mathrm{~s}$ to disrupt the fecal material. The samples were then shaken for $30 \mathrm{~min}$ at room temperature in a shaker incubator at $50 \mathrm{rpm}$. After shaking, the samples were allowed to sit upright at room temperature for an additional $30 \mathrm{~min}$. With a sterile disposable pipette, $5 \mathrm{~mL}$ of liquid from the top portion of the tube was placed into a second $50-\mathrm{mL}$ tube containing $25 \mathrm{~mL}$ of $0.9 \%$ hexadecylpyridinium chloride in $1 / 2 \times$ brain heart infusion broth, and was incubated at $37 \pm 2^{\circ} \mathrm{C}$ overnight ( 18 to $24 \mathrm{~h}$ ). After incubation, the tubes were centrifuged at $900 \times g$ for $20 \pm 2 \mathrm{~min}$, and the supernatant discarded. The pellet was resuspended in $1 \mathrm{~mL}$ of antibiotic brew (TREK Diagnostic Systems, Cleveland, OH; ESP para-JEM AS for antibiotic brew), vortexed for $15 \mathrm{~s}$, and incubated at $37 \pm 2^{\circ} \mathrm{C}$ overnight (18 to $24 \mathrm{~h}$ ). Following incubation, each sample was vortexed vigorously for $15 \mathrm{~s}$. Two hundred fifty microliters of each sample was inoculated onto each of 4 tubes of HEYA (Becton Dickinson BBL) with mycobactin J, amphotericin $\mathrm{B}$, naladixic acid, and vancomycin using a sterile, disposable extended length pipette tip. The HEYA tubes were recapped loosely, tipped to spread the sample across the slant face, and incubated at 37 $\pm 2^{\circ} \mathrm{C}$ in a slanted position for 3 to $5 \mathrm{~d}$ to allow the surface of the slant to dry. Once the slant surfaces were dry, the tube caps were tightened, and the slants were placed upright in the incubator. The slants were evaluated for typical MAP growth and contamination at 8 and $16 \mathrm{wk}$, and colony counts were recorded. One colony was removed from samples with typical growth, for acid-fast staining (see Acid-Fast Staining section below), and extracted for PCR analysis using the master mix and PCR parameters described below to confirm the presence of MAP. Samples were considered positive for MAP if they showed typical growth on HEYA and were confirmed by acid-fast staining and PCR.

\section{Acid-Fast Staining}

The HEYA cultures showing typical growth were acid-fast stained. One typical colony was mixed with $100 \mu \mathrm{L}$ of sterile water and a loopful of the suspension was placed on a microscope slide and allowed to airdry. Once dry, the slides were heat-fixed and stained with an acid-fast stain kit according to manufacturer's directions (ENG Scientific, Clifton, NJ). After staining, the samples were observed microscopically for the presence of acid-fast bacilli.

\section{Fecal Extraction and Direct PCR}

Two grams of fecal material was placed into a sterile $15-\mathrm{mL}$ plastic conical tube containing $4 \mathrm{~mL}$ of sterile water. The sample was vigorously vortexed for $15 \mathrm{~s}$ and allowed to sit upright at room temperature for $10 \mathrm{~min}$. A sterile disposable Pasteur pipette was used to remove $1.5 \mathrm{~mL}$ of the liquid portion. The liquid sample was placed into a $2-\mathrm{mL}$ tube containing $1 \mathrm{~g}$ of zirconia/silica beads (Biospec Products, Bartlesville, OK). The tubes were then centrifuged at $13,000 \times g$ for $10 \mathrm{~min}$. The supernatant was discarded, and the pellet was resus- 
pended into $400 \mu \mathrm{L}$ of sterile water. The samples were incubated at $95^{\circ} \mathrm{C}$ for $10 \mathrm{~min}$ and bead beaten for $45 \mathrm{~s}$ at 6,500 rpm in the MagNA Lyser instrument (Roche Diagnostics, Basel, Switzerland). Samples were then centrifuged at $13,000 \times g$ for $10 \mathrm{~min}$ in a bench-top centrifuge. The DNA was isolated using the High Pure PCR Template Preparation Kit (Roche Diagnostics) as follows: $500 \mu \mathrm{L}$ of the resulting supernatant was combined with $500 \mu \mathrm{L}$ of High Pure binding buffer and 250 $\mu \mathrm{L}$ of absolute isopropanol and vortexed for $15 \mathrm{~s}$. Six hundred microliters of the resulting solution was added to a high pure column and centrifuged as recommended. After centrifugation the remaining solution was added to the column and the centrifugation was repeated. The column was washed once with $500 \mu \mathrm{L}$ of inhibitor removal solution and 3 times with wash solution. The DNA was eluted in a volume of $100 \mu \mathrm{L}$. The extracted DNA was frozen until PCR analysis.

Each PCR reaction capillary contained $1 \mu M$ each of P90: (5'-GAA GGG TGT TCG GGG CCG TCG CTT AGG-3') and P91: (5'-GGC GTT GAG GTC GAT CGC CCA CGT GAC-3') primers (IDT Inc., Coralville, IA), $10 \mu \mathrm{L}$ of Eva Green $2 \times$ Basic Mix (Biotium Inc., Hayward, CA), $1 \mu M \mathrm{MgCl}_{2}, 3 \mu \mathrm{L}$ of PCR-grade water, 0.5 $\mathrm{mg} / \mathrm{mL}$ of BSA, 6 units of Roche FastStart Taq polymerase, and $2 \mu \mathrm{L}$ of purified DNA.

Reactions were performed on the LightCycler instrument (Roche Diagnostics). Amplification conditions were as follows: $10 \mathrm{~min}$ at $95^{\circ} \mathrm{C} ; 40$ cycles of $10 \mathrm{~s}$ at $95^{\circ} \mathrm{C}$, $5 \mathrm{~s}$ at $75^{\circ} \mathrm{C}$, and $16 \mathrm{~s}$ at $72^{\circ} \mathrm{C}$ with a single fluorescence acquisition during the extension cycle. Melting curve analysis was performed as follows: samples were heated to $95^{\circ} \mathrm{C}$, then immediately cooled to $70^{\circ} \mathrm{C}$ and held for $1 \mathrm{~min}$. Samples were then heated to $99^{\circ} \mathrm{C}$ at a rate of $0.1^{\circ} \mathrm{C}$ with continuous fluorescence monitoring. Samples were then cooled to $40^{\circ} \mathrm{C}$. Samples, which demonstrated an increase in fluorescence during amplification and a corresponding melting peak between 90 and $92^{\circ} \mathrm{C}$, were considered positive.

\section{Serum ELISA}

The Rocky Mountain Regional Animal Health Laboratory, Denver, Colorado, was contracted to conduct serum ELISA tests per the manufacturer's directions using the Parachek Johne's Absorbed EIA (BioCor Animal Health, Omaha, NE).

\section{Controls}

Each day that samples were processed for culture, controls consisting of an uninnoculated slant and a slant inoculated with viable MAP were included to demonstrate media sterility and productivity respectively.
Each set of 30 samples processed for PCR contained a master mix negative with sterile water substituted for a sample and a positive control consisting of known MAP DNA to show PCR reagent sterility and productivity, respectively.

\section{Statistical Methods}

Proportions (in percentages) of MAP positivity by culture, PCR, and ELISA were calculated based on 250 serum samples, and the associated $95 \%$ confidence intervals were derived using the exact binomial distribution. In addition, the differences in proportions between culture and PCR, between culture and ELISA, and between PCR and ELISA were compared using the McNemar's test for paired data. A $P$-value of $<0.05$ was claimed statistically significant. Kappa scores for agreement between tests were also calculated. Using culture as the definitive test (Collins, 1996), values (treated as proportions) of sensitivity and specificity and their corresponding 95\% confidence intervals (CI) were also calculated, with or without stratifying specimen by culture results ( 0 to $<10 \mathrm{cfu}, 10$ to $<40 \mathrm{cfu}, 40+$ cfu). Likelihood ratios were calculated as described by Hayden and Brown (1999). Predictive value of a positive test was calculated as (true positives)/(true positives + false positives), and the predictive value of a negative test was calculated as (true negatives)/(true negatives + false negatives).

\section{RESULTS}

Two hundred fifty animals were included in this study. Overall, 67/250 (26.8\%; 95\% CI of 21.4 to $32.8 \%$ ) animals were culturally confirmed to be shedding MAP. The PCR and ELISA detected 74/250 (29.6\%; 95\% CI of 24 to $35.7 \%$ ) and $25 / 250$ (10\%; 95\% CI of 6.6 to $14.4 \%$ ), respectively. Agreement between diagnostic tests was assessed using a Kappa test. The PCR vs. culture had a Kappa score of 0.54 (95\% CI of 0.42 to 0.65), ELISA vs. culture had a Kappa score of 0.36 (95\% CI of 0.24 to 0.49), and ELISA vs. PCR had a Kappa score of 0.35 (95\% CI of 0.23 to 0.47). Culture and PCR were able to detect more Johne's-positive animals than ELISA $(P<$ 0.0001; Table 1). Overall, direct fecal PCR was $70.2 \%$ sensitive and $85.3 \%$ specific when using culture as the gold standard. The ELISA method was $31.3 \%$ sensitive and $97.8 \%$ specific (Table 2). Overall, PCR had a positive predictive value of $63.5 \%$ (95\% CI of 51.5 to $74.4 \%$ ) and a negative predictive value of $88.6 \%$ (95\% CI of 83.0 to $92.9 \%$ ) when compared with culture. Overall, ELISA had a positive predictive value of $84.0 \%$ (95\% CI of 63.9 to $95.5 \%$ ) and a negative predictive value of 79.6\% (95\% CI of 73.7 to $84.6 \%$ ) when compared with 
Table 1. Mycobacterium avium ssp. paratuberculosis-positive samples by culture, PCR, and ELISA

\begin{tabular}{lccc}
\hline Test & Total & $\begin{array}{c}\text { Number } \\
\text { positive }\end{array}$ & $\%,{ }^{1}$ CI \\
\hline Culture & 250 & $67^{\mathrm{a}}$ & $26.8,21.4$ to 32.8 \\
PCR & 250 & $74^{\mathrm{a}}$ & $29.6,24.0$ to 35.7 \\
ELISA & 250 & $25^{\mathrm{b}}$ & $10.0,6.6$ to 14.4 \\
\hline
\end{tabular}

${ }^{\mathrm{a}, \mathrm{b}}$ Numbers with different superscripts differ $(P<0.05)$.

${ }^{1} 95 \%$ confidence interval.

culture. Overall, PCR had a positive likelihood ratio (Pos LR) of 4.76 and ELISA had a Pos LR of 14.22 when using HEYA culture as the gold standard. The PCR had a negative likelihood ratio (Neg LR) of 0.35 and ELISA had a Neg LR of 0.70 when using HEYA culture as the gold standard.

When culture reported $<10 \mathrm{cfu}$ the sensitivity and specificity of PCR were 57.1 and $85.3 \%$, respectively, the sensitivity and specificity of ELISA were 4.8 and $97.8 \%$, respectively (Table 3 ). The positive and negative predictive value of PCR was $48.1 \%$ (95\% CI of 34.0 to $62.4 \%$ ) and $89.1 \%$ (95\% CI of 83.4 to $93.3 \%$ ), respectively. The ELISA had a positive and negative predictive value of $33.3 \%$ (95\% CI of 4.3 to $77.7 \%$ ) and $80.1 \%$ (95\% CI of 74.2 to $85.2 \%$ ), respectively. The PCR had a Pos LR and Neg LR of 3.88 and 0.50, respectively. The ELISA had a Pos LR and Neg LR of 2.18 and 0.97 , respectively.

When culture reported 10 to $<40 \mathrm{cfu}$, the sensitivity of PCR and ELISA were 75 and 50\%, respectively. When culture reported $\geq 40 \mathrm{cfu}$, the sensitivity of PCR and ELISA were 100 and $88.2 \%$, respectively. Specificity could not be calculated at these levels because there were no culture-negative samples (Table 3 ).

\section{DISCUSSION}

The objectives of this study were to estimate the sensitivity and specificity of the direct fecal PCR test and compare the abilities of direct PCR and serum ELISA to correctly identify animals shedding MAP. Overall, the ability of PCR and culture to detect positive animals was not different. However, ELISA detected fewer positive animals than PCR or culture. The likelihood ratios calculated for both PCR and ELISA using HEYA culture as the definitive test for disease indicate that overall, a positive ELISA result is more likely associated with a diseased animal. This is not surprising because animals that produce an immune response are typically in the later stages of disease. However, a negative ELISA result was less likely to correctly predict a nondiseased animal. When MAP shedding was $<10 \mathrm{cfu}$, PCR had a higher Pos LR and a lower Neg LR than ELISA, indicating a higher probability of predicting diseased or nondiseased animals, respectively. Likelihood ratios are excellent tools for evaluating the discriminative power of diagnostic tests. However, when it is important to avoid false positives and false negatives, sensitivity and specificity should also be considered (Dujardin et al., 1994).

The overall sensitivity and specificity of the ELISA used in this study was similar to the specificity found in another study (Collins et al., 2005) that compared commercial ELISA. The sensitivity and specificity for both PCR and ELISA improved as level of fecal shedding increased. The sensitivity of fecal PCR was better than ELISA across all shedding level categories when using culture as the gold standard.

These findings contradicted recent work by Wells et al. (2006), which found that ELISA outperformed PCR in light and moderate shedding animals. The Taqmanbased PCR used in that study was only able to detect $76 \%$ of the heavy fecal shedders tested. The greater sensitivity of PCR in the current study could be attributed to the number of copies of the DNA sequence we targeted. The MAP genome contains between 15 and 20 copies of the IS900 sequence (Green et al., 1989) and has been widely used as a diagnostic target because of its high copy number and uniqueness to MAP. Wells et al. (2006) targeted ISMav2, which is thought to be present in at least 3 copies per genome (Strommenger et al., 2001). Fewer copies of the target sequence may be one possible reason for decreased sensitivity in the Wells study. In addition, bead beating to mechanically disrupt the cells was used in our study and has been

Table 2. Sensitivity and specificity of Mycobacterium avium ssp. paratuberculosis PCR and ELISA using Herrold's egg yolk agar culture as a gold standard

\begin{tabular}{lcccccccr}
\hline Test & No./Total & $\begin{array}{c}\text { Sensitivity } \\
(\%)\end{array}$ & $\begin{array}{c}\text { CI } \\
(\%)\end{array}$ & No./Total & $\begin{array}{c}\text { Specificity } \\
(\%)\end{array}$ & $\begin{array}{c}\mathrm{CI}^{1} \\
(\%)\end{array}$ & $\begin{array}{c}\text { Pos } \\
\text { LR }^{2}\end{array}$ & $\begin{array}{r}\text { Neg } \\
\mathrm{LR}^{3}\end{array}$ \\
\hline PCR & $47 / 67$ & 70.2 & $57.7-80.7$ & $156 / 183$ & 85.3 & $79.3-90.1$ & 4.76 & 0.35 \\
ELISA & $21 / 67$ & 31.3 & $20.6-43.8$ & $179 / 183$ & 97.8 & $94.5-99.4$ & 14.22 & 0.70 \\
\hline
\end{tabular}

${ }^{1} 95 \%$ confidence interval.

${ }^{2}$ Positive likelihood ratio.

${ }^{3}$ Negative likelihood ratio. 
Table 3. Sensitivity and specificity of Mycobacterium avium ssp. paratuberculosis PCR and ELISA using culture as gold standard at low, medium, and high shedding levels

\begin{tabular}{|c|c|c|c|c|c|c|c|c|c|}
\hline Culture results & Test & No./Total & $\begin{array}{c}\text { Sensitivity } \\
(\%)\end{array}$ & $\begin{array}{l}\mathrm{CI}^{1} \\
(\%)\end{array}$ & No./Total & $\begin{array}{c}\text { Specificity } \\
(\%)\end{array}$ & $\begin{array}{l}\text { CI } \\
(\%)\end{array}$ & $\begin{array}{l}\text { Pos } \\
L^{2}\end{array}$ & $\begin{array}{l}\text { Neg } \\
\mathrm{LR}^{3}\end{array}$ \\
\hline \multicolumn{10}{|l|}{$<10 \mathrm{cfu}$} \\
\hline & PCR & $24 / 42$ & 57.1 & $41.0-72.3$ & $156 / 183$ & 85.3 & $79.3-90.1$ & 3.88 & 0.50 \\
\hline & ELISA & $2 / 42$ & 4.8 & $0.3-16.2$ & $179 / 183$ & 97.8 & $94.5-99.4$ & 2.18 & 0.97 \\
\hline 10 to $<40 \mathrm{cfu}$ & PCR & $6 / 8$ & 75.0 & $34.9-96.8$ & $\mathrm{NA}^{4}$ & NA & NA & NA & NA \\
\hline & ELISA & $4 / 8$ & 50.0 & $15.7-84.3$ & $\mathrm{NA}$ & NA & NA & NA & $\mathrm{NA}$ \\
\hline \multicolumn{10}{|l|}{$\geq 40 \mathrm{cfu}$} \\
\hline & ELISA & $15 / 17$ & 88.2 & $63.6-98.5$ & NA & NA & NA & NA & NA \\
\hline
\end{tabular}

\footnotetext{
${ }^{1} 95 \%$ confidence interval.

${ }^{2}$ Positive likelihood ratio.

${ }^{3}$ Negative likelihood ratio.

${ }^{4} \mathrm{NA}=$ not applicable.
}

shown to recover 65 to $95 \%$ more MAP DNA from manure and soil samples than cell extraction buffers alone (Cook and Britt, 2007). The recovery of more DNA and the greater number of target sequence in the genome would greatly influence the sensitivity of the test.

Conversely, the overall specificity of the fecal PCR method (85.3\%) described here was slightly lower than both the ELISA (97.8\%) used in this study and the Taqman PCR (99.7\%) described by Wells et al. (2006). One explanation for this may be that many of the cultures observed in this study had fewer than $10 \mathrm{cfu} / \mathrm{g}$. Although, HEYA culture is the long-standing method, often used as a gold standard for comparison, it has been observed that the decontamination procedure is detrimental to MAP growth (Johansen et al., 2006).

Samples with low numbers of MAP that are subjected to decontamination may return negative culture results. Polymerase chain reaction, which does not incorporate a decontamination step, may detect these low shedding animals. Therefore, positive PCR results would be recorded as false positives because the corresponding culture returned a negative result, effectively reducing the calculated specificity. The Taqman study (Wells et al., 2006) used known negative animals to test specificity, thereby reducing the potential for such an error. Cattle used in this study were of unknown disease status. Culture, although the gold standard, has an estimated sensitivity of 30 to $50 \%$ (Whitlock et al., 2000). Using culture as the definitive test may have introduced some error in the sensitivity and specificity calculations for the PCR and ELISA methods because we cannot distinguish animals that were truly negative from low shedders incorrectly classified as negative due to intermittent shedding, low numbers of bacteria in feces, or decontamination die-off. Previous reports assessing the validity of ELISA-based methods have routinely used culture as the comparative test to calculate sensitivity and specificity (Collins et al., 1991; Cox et al., 1991; Milner et al., 1990; Sockett et al., 1992; Sweeney et al., 1995). Isolation of MAP from tissue or feces on bacteriologic media has been the mainstay of paratuberculosis detection for nearly a century and remains the most widely used diagnostic test for infection (Collins, 1996).

Polymerase chain reaction-based assays can crossreact with other genetically similar organisms if primers are not designed properly and PCR cycling parameters are not optimized. Assays that do cross-react can greatly influence the interpretation of results if that cross-reactivity is not known. The PCR assay used in this study was evaluated with various environmental mycobacteria to demonstrate the analytical specificity of the primers and ensure that the assay was not crossreacting with other mycobacteria that may be present in the fecal material. The assay showed no cross-reactivity with the isolates tested (N. M. Parrish, R. P. Radcliff, B. J. Brey, J. L. Anderson, D. L. Clark Jr., J. J. Koziczkowski, C. G. Ko, N. D. Goldberg, D. A. Brinker, R. A. Carlson, J. D. Dick, and J. L. E. Ellingson; Marshfield Clinic, St. Joseph Medical Ctr., Towson, MD; and Johns Hopkins Univ., Baltimore, MD; unpublished data). In contrast, some assays targeting ISMav2, IS900, and F57 have been shown to cross-react with other mycobacteria (Möbius et al., 2008).

The use of PCR and its increased sensitivity capabilities also carries the risk of cross-contamination of DNA between samples. Caution must be taken when using PCR because small amounts of target DNA contamination may lead to false positives and decreased specificity. This study incorporated various safeguards to try to reduce the potential for cross-contamination. Some of these included having separate designated areas for DNA extraction, PCR reagent setup, and template addition. Areas and pipettors were decontaminated with 
DNase and ultraviolet lamps after use. The use of the LightCycler excludes the need for gel-based detection. This allows for the closed capillary system to remain closed reducing the risk of amplicon contamination after cycling. Reagent negatives were also amplified alongside samples to monitor for contamination. Although cross-contamination can be an issue with any test, especially one as sensitive as PCR, with the proper precautionary steps the probability of cross-contamination is greatly reduced.

Regardless of lower specificity, the current PCR assay showed much greater sensitivity than the ELISA assay and the described previously direct PCR assay (Wells et al., 2006), allowing for the identification of infected animals across all shedding levels without the need for further confirmation. The assay is fast; one sample can be fully processed in under $3 \mathrm{~h}$ compared with $16 \mathrm{wk}$ for traditional culture. Greater sensitivity of the PCR assay will allow practitioners to identify heavy fecal shedders and a greater proportion of light shedders within herds as compared with serum ELISA testing. The greater sensitivity may also allow the testing of pooled fecal samples, making whole-herd and environmental sampling more economical. This may help make management decisions easier for practitioners and producers.

\section{ACKNOWLEDGMENTS}

This work was supported through funding from the Marshfield Clinic Research Foundation. We would also like to thank Julie Wendler of the Dairyland Animal Clinic (Owen, WI) and Mike Peters of the USDA Dairy Animal Forage Facility (Sauk Prairie, WI) for help in the collection of samples and recruitment of animals used in this study.

\section{REFERENCES}

Bulaga, L. L. 1998. US voluntary Johne's disease herd status program for cattle. Pages 420-433 in Proc. 102nd Annu. Meet. US Anim. Health Assoc., Pat Campbell and Assoc., Carter Printing, Richmond, VA.

Christensen, J., and I. A. Gardner. 2000. Herd-level interpretation of test results for epidemiologic studies of animal diseases. Prev. Vet. Med. 45:83-106.

Collins, M. T., D. C. Sockett, S. Ridge, and J. C. Cox. 1991. Evaluation of a commercial enzyme-linked immunosorbent assay for Johne's disease. J. Clin. Microbiol. 29:272-276.

Collins, M. T. 1996. Diagnosis of paratuberculosis. Vet. Clin. North Am. Food Anim. Pract. 12:357-371.

Collins, M. T., S. J. Wells, K. R. Petrini, J. E. Collins, R. D. Schultz, and R. H. Whitlock. 2005. Evaluation of five antibody detection tests for diagnosis of bovine paratuberculosis. Clin. Diagn. Lab. Immunol. 12:685-692.

Cook, K. L., and J. S. Britt. 2007. Optimization of methods for detecting Mycobacterium avium subsp. paratuberculosis in environmental samples using quantitative, real-time PCR. J. Microbiol. Methods 69:154-160.
Cox, J. C., D. P. Drane, S. L. Jones, S. Ridge, and A. R. Milner. 1991. Development and evaluation of a rapid absorbed enzyme immunoassay test for the diagnosis of Johne's disease in cattle. Aust. Vet. J. 68:157-160.

Dujardin, B., J. Van den Ende, A. Van Gompel, J. P. Unger, and P. Van der Stuyft. 1994. Likelihood ratios: A real improvement in clinical decision making? Eur. J. Epidemiol. 10:29-36.

Eamens, G. J., R. J. Whittington, I. B. Marsh, J. J. Turner, V. Saunders, P. D. Kemsley, and D. Rayward. 2000. Comparative sensitivity of various faecal culture methods and ELISA in dairy cattle herds with endemic Johne's disease. Vet. Microbiol. 77:357-368.

Ellingson, J. L., C. A. Bolin, and J. R. Stabel. 1998. Identification of a gene unique to Mycobacterium avium subspecies paratuberculosis and application to diagnosis of paratuberculosis. Mol. Cell. Probes 12:133-142.

Green, E. P., M. L. Tizard, M. T. Moss, J. Thompson, D. J. Winterbourne, J. J. McFadden, and J. Hermon-Taylor. 1989. Sequence and characteristics of IS900, an insertion element identified in a human Crohn's disease isolate of Mycobacterium paratuberculosis. Nucleic Acids Res. 17:9063-9073.

Harris, N. B., and R. G. Barletta. 2001. Mycobacterium avium subsp. paratuberculosis in veterinary medicine. Clin. Microbiol. Rev. 14:489-512.

Hayden, S. R., and M. D. Brown. 1999. Likelihood ratio: A powerful tool for incorporating the results of a diagnostic test into clinical decisionmaking. Ann. Emerg. Med. 33:575-580.

Johansen, K. A., E. E. Hugen, and J. B. Payeur. 2006. Growth of Mycobacterium avium subsp. paratuberculosis in the presence of hexadecylpyridinium chloride, natamycin, and vancomycin. J. Food Prot. 69:878-883.

Jorgensen, J. B. 1977. Survival of Mycobacterium paratuberculosis in slurry. Nord. Vet. Med. 29:267-270.

Larsen, A. B., B. S. Merkal, and T. H. Vardman. 1956. Survival time of Mycobacterium paratuberculosis. Am. J. Vet. Res. 17:549-551.

Miller, J. M., A. L. Jenny, and J. L. Ellingson. 1999. Polymerase chain reaction identification of Mycobacterium avium in formalinfixed, paraffin-embedded animal tissues. J. Vet. Diagn. Invest. 11:436-440.

Milner, A. R., W. N. Mack, K. J. Coates, J. Hill, I. Gill, and P. Sheldrick. 1990. The sensitivity and specificity of a modified ELISA for the diagnosis of Johne's disease from a field trial in cattle. Vet. Microbiol. 25:193-198.

Möbius, P., H. Hotzel, A. Raßach, and H. Köhler. 2008. Comparison of 13 single-round and nested PCR assays targeting IS900, ISMav2, f57 and locus 255 for detection of Mycobacterium avium subsp. paratuberculosis. Vet. Microbiol. 126:324-333.

Mura, M., T. J. Bull, H. Evans, K. Sidi-Boumedine, L. McMinn, G. Rhodes, R. Pickup, and J. Hermon-Taylor. 2006. Replication and long-term persistence of bovine and human strains of Mycobacterium avium subsp. paratuberculosis within Acanthamoeba polyphaga. Appl. Environ. Microbiol. 72:854-859.

NAHMS (National Animal Health Monitoring System). 1996. Part I: Reference of 1996 Dairy Management Practices. USDA: APHIS: VS; CEAH, National Animal Health Monitoring System, Fort Collins, $\mathrm{CO}$

Raizman, E. A., S. J. Wells, S. M. Godden, R. F. Bey, M. J. Oakes, D. C. Bentley, and K. E. Olsen. 2004. The distribution of Mycobacterium avium ssp. paratuberculosis in the environment surrounding Minnesota dairy farms. J. Dairy Sci. 87:2959-2966.

Sockett, D. C., T. A. Conrad, C. B. Thomas, and M. T. Collins. 1992. Evaluation of four serological tests for bovine paratuberculosis. J. Clin. Microbiol. 30:1134-1139.

Stabel, J. R. 1997. An improved method for cultivation of Mycobacterium paratuberculosis from bovine fecal samples and comparison to three other methods. J. Vet. Diagn. Invest. 9:375-380.

Stabel, J. R., S. J. Wells, and B. A. Wagner. 2002. Relationships between fecal culture, ELISA, and bulk tank milk test results for Johne's disease in US dairy herds. J. Dairy Sci. 85:525-531.

Strommenger, B., K. Stevenson, and G. F. Gerlach. 2001. Isolation and diagnostic potential of ISMav2, a novel insertion sequencelike element from Mycobacterium avium subspecies paratuberculosis. FEMS Microbiol. Lett. 196:31-37. 
Sweeney, R. W., R. H. Whitlock, C. L. Buckley, and P. A. Spencer. 1995. Evaluation of a commercial enzyme-linked immunosorbent assay for the diagnosis of paratuberculosis in dairy cattle. J. Vet. Diagn. Invest. 7:488-493.

Wells, S. J., R. H. Whitlock, C. J. Lindeman, and T. Fyock. 2002. Evaluation of bacteriologic culture of pooled fecal samples for detection of Mycobacterium paratuberculosis. Am. J. Vet. Res. 63:1207-1211.

Wells, S. J., S. M. Godden, C. J. Lindeman, and J. E. Collins. 2003. Evaluation of bacteriologic culture of individual and pooled fecal samples for detection of Mycobacterium paratuberculosis in dairy cattle herds. J. Am. Vet. Med. Assoc. 223:1022-1025.

Wells, S. J., M. T. Collins, K. S. Faaberg, C. Wees, S. Tavornpanich, K. R. Petrini, J. E. Collins, N. Cernicchiaro, and R. H. Whitlock. 2006. Evaluation of a rapid fecal PCR test for the detection of
Mycobacterium avium ssp. paratuberculosis in dairy cattle. Clin. Vaccine Immunol. 13:1125-1130.

Whitlock, R. H., S. J. Wells, R. W. Sweeney, and J. Van Tiem. 2000. ELISA and fecal culture for paratuberculosis (Johne's disease): Sensitivity and specificity of each method. Vet. Microbiol. 77:387-398.

Whittington, R. J., S. Fell, D. Walker, S. McAllister, I. Marsh, E. Sergeant, C. A. Taragel, D. J. Marshall, and I. J. Links. 2000. Use of pooled fecal culture for sensitive and economic detection of Mycobacterium avium subsp. paratuberculosis infection in flocks of sheep. J. Clin. Microbiol. 38:2550-2556.

Whittington, R. J., I. B. Marsh, and R. H. Whitlock. 2001. Typing of IS1311 polymorphisms confirms that bison (Bison bison) with paratuberculosis in Montana are infected with a strain of $\mathrm{Myco-}$ bacterium avium subsp. paratuberculosis distinct from that occurring in cattle and other domesticated livestock. Mol. Cell. Probes 15:139-145. 